\title{
A CASE OF AGGLUTINATION AND HEMOLYSIS OF ERYTHROCYTES CAUSED BY THE PATIENT'S OWN PLASMA
}

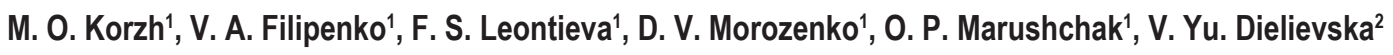 \\ ${ }^{1}$ Sytenko Institute of Spine and Joint Pathology of the National Academy of Medical Sciences of Ukraine, \\ Kharkiv, Ukraine \\ ${ }^{2}$ Kharkiv National Medical University, Kharkiv, Ukraine
}

\begin{abstract}
The aim of the work was to study the agglutination and hemolysis of erythrocytes under different conditions in vitro in a patient with unknown cause of anemia and concomitant secondary instability of endoprosthesis. Material and methods. One percent (1\%) suspension of erythrocytes of a woman, 61 years old, A (II) Rh- (negative) presented with anemia was incubated with her serum and plasma at $\mathrm{pH} 7.3, \mathrm{pH} 5.8$ and 9.0, as well as with $\lg M \alpha$ and $\beta$ antibodies. Unithiol was used to destroy IgM antibodies. The samples were incubated for 12 hours at $37^{\circ} \mathrm{C}$, and the presence of the agglutination and hemolysis was evaluated. Results. The incubation of the plasma with unwashed erythrocytes of the patient led to the agglutination of the erythrocytes and the usage of the complement led to the hemolysis. After inactivation of IgM in the plasma the agglutination was absent and the hemolysis was present under usual conditions and at $\mathrm{pH} 5.8$, whereas at $\mathrm{pH} 8.0$ the hemolysis was attenuated, however a slight degree agglutination appeared. The usage of the complement led to the agglutination and the hemolysis, absent at $\mathrm{pH}$ 8.0. The plasma incubated with washed red blood cells and the complement led to the hemolysis. The incubation of the serum with washed erythrocytes led to the hemolysis at pH 5.8, attenuated after the usage of the complement. The contact of terbinophine with plasma and unwashed red blood cells led to the absence of both the hemolysis and the agglutination. Candida lusitaniae growth was detected in the plasma. Conclusions. The agglutination of unwashed erythrocytes by own plasma, attenuated in the alkaline medium and enhanced in the acid medium, as well as the absence of the agglutination after the usage of terbinophine and the hemolysis in the presence of the complement might be the signs of mycogenic and autoimmune origin of anemia with the activation of autoimmune complement - binding antibodies.
\end{abstract}

Key words: autoagglutination, hemolysis, erythrocytes, complement, antigen

Corresponding authors: Valentyna Dielievska, MD, e-mail: valentinka_1987@ukr.net 


\section{INTRODUCTION}

A utoagglutination, known as agglutination of erythrocytes by a subject's own serum, can occur in the course of different autoimmune disorders. Red blood cell (RBC) autoantibodies have variable clinical significance - from benign to lifethreatening scenarios and may signal an underlying disease [1].

RBC autoantibodies increase with age and can be warm-reacting, if they act at $37^{\circ} \mathrm{C}$, or cold-reacting, if the optimal temperature is less than $30^{\circ} \mathrm{C}[2,3]$. Cold-reacting agglutinins are known to result from infections with mycoplasma, infectious mononucleosis, lymphoid malignant disorders and are potent to fix the complement, that may lead to the hemolysis and agglutination when patients are exposed to low temperatures.

In autoimmune hemolytic anemia (AIHA) antibodies act on the erythrocytes at temperatures below $37^{\circ} \mathrm{C}$, with their maximal activity at $4^{\circ} \mathrm{C}$ without hemolysis. The antibodies are mostly of the IgM class and partly of the $\mathrm{lgG}$. The diagnosis of auto-agglutination can be confirmed by the direct antiglobulin test (DAT) using Coomb's serum [4], polyspecific antihuman globulin, with positive reactivity for erythrocytes coated with immunoglobulins or complement in $75 \%$ of cases. A positive DAT may occur in cases of IgG sensitization.

Warm RBC autoantibodies were associated with Bcell lymphomas, macroglobulinemias, autoimmune disorders, systemic lupus erythematosus and may also cause AlHA. Patients with warm RBC autoantibodies do not present spontaneous agglutination of the erythrocytes, but can have severe hemolysis with symptoms of anemia. Warm RBC autoantibodies are detected with the help of monospecific anti-lgG, whereas cold RBC autoantibodies - with monospecific anticomplement reagents.

The optimal method for removing the autoantibody is adsorption. Chloroquine or enzymes are used to remove the autoantibodies bound on the erythrocytes, which are then incubated with the patient's serum, that causes absorption of the autoantibodies on $\mathrm{RBC}$, leaving alloantibodies for identification.

The significance of RBC autoantibodies in a complicated course of the postoperative period has not been well understood.

Therefore, we performed a study about the causative agents of auto-agglutination in a patient with infectious complications after surgery.

\section{MATERIALS AND METHODS}

A blood sample for the study was drawn from a 61-year-old female patient with a secondary instability of the right knee joint two months after the removal of her endoprosthesis and replacement of the defect with a metal-cement spacer. To obtain the serum, the blood was kept during 30 minutes at $20^{\circ} \mathrm{C}$ and then centrifuged at $1500 \mathrm{rpm}$ for 15 minutes. The erythrocytes and plasma were obtained after adding heparin (in dilution - heparin:whole blood $=1: 100$ ). The red blood cells were also obtained from non-heparinized blood after removal of the serum. Unwashed and washed red blood cells were used. The erythrocytes were washed three times with a buffered $0.9 \% \mathrm{NaCl}$ solution ( $\mathrm{pH} 7.3$ ) by centrifugation at $1000 \mathrm{rpm}$ for 10 minutes and removal of the supernatant. The agglutination reaction was used to determine the groupspecific characteristics. The patient's erythrocytes were grouped as A (II) Rh - (negative). A drop of $1 \%$ red cell suspension was incubated with the patient's own serum or plasma at $\mathrm{pH} 7.3$ and also in buffer solutions with $\mathrm{pH} 5.8$ and 9.0 , as well as with $\operatorname{lgM} \alpha$ and $\beta$ antibodies (MyBioSource, USA). Unithiol was used to destroy antibodies of the IgM class in the serum and plasma. The complement of the guinea pig (Pharmstandard-Biolek, Ukraine) was used in dilution with the serum or plasma in proportion 1:1. The samples were placed in a thermostat for 12 hours at $37^{\circ} \mathrm{C}$, and the presence of agglutination, hemolysis and shadows of red blood cells was evaluated. The hemagglutination reaction of erythrocytes was assessed visually and under a microscope, taking into account both the titer and the agglutination intensity (according to Score) [5]. The severity of the complement-dependent hemolysis of the erythrocytes was assessed visually and spectrophotometrically at a $560 \mathrm{~nm}$ wavelength [6]. Positive control for the presence of hemolysis and agglutination was achieved with a sample of the erythrocytes under the exposure of $0.4 \% \mathrm{NaCl}$ solution (osmotic hemolysis), negative control - with $0.9 \% \mathrm{NaCl}$ solution. 0.1 M Na2HPO4/ $\mathrm{NaH} 2 \mathrm{PO} 4$ buffer systems with $\mathrm{pH} 5.8$ and 8.0 were used in the experiment. The $\mathrm{pH}$ of the medium was monitored with an universal ionomer EV-74 using microelectrodes.

\section{RESULTS}

Complete blood count of the patient revealed an increase in stab neutrophils to $7 \%$, eosinophils to $2 \%$ and ESR to $20 \mathrm{~mm} / \mathrm{h}$, as well as decreases of hemoglobin to $102 \mathrm{~g} / \mathrm{l}$ and red blood cells to $4.01 \times 10^{12} \mathrm{~g} / \mathrm{l}$. The biochemical analysis of the blood found an in- 
crease of glycoproteins up to $0.62 \mathrm{~g} / \mathrm{l}$. Bacteriological investigation of the synovial fluid showed no growth. Morphological examination of the synovial fluid revealed the following: yellow color, cloudy, bloody precipitate, cell number $=0.1 \times 109 / \mathrm{l}$, neutrophils $=25 \%$, synoviocytes $=9 \%$, macrophages $=2 \%$ and erythrocytes $=$ in the entire field of the view.

\section{Investigation of agglutination and hemolysis with unwashed erythrocytes}

Incubation of the plasma of the blood group (II) A ( $\beta$, anti-B) $\mathrm{Rh}$ - with unwashed erythrocytes in a thermostat at $37^{\circ} \mathrm{C}$ for 12 hours resulted in a severe agglutination with a transparent supernatant (Table 1). After the plasma came in contact with erythrocytes at $20^{\circ} \mathrm{C}$ the agglutination was not observed.

After addition of the complement to the plasma with unwashed erythrocytes, the agglutination was attenuated, but the hemolysis was present, with the supernatant becoming pink colored.

To define the degree of the agglutination at different $\mathrm{pH}$, plasma and unwashed erythrocytes were kept at $\mathrm{pH} 5.8$ and 8.0. Thus, at $\mathrm{pH} 5.8$ the agglutination was present, however at $\mathrm{pH} 8.0$ the agglutination was attenuated.

To destroy the antibodies of IgM class in the plasma we applied unithiol, that led to the disappearance of the agglutination at usual conditions and at $\mathrm{pH} 5.8$, with the supernatant becoming red colored. At pH 8.0 the supernatant remained transparent and a slight degree agglutination appeared. After the complement came in contact with unwashed erythrocytes and plasma treated with unithiol under normal conditions the agglutination with shadows of erythrocytes was revealed, but was absent at $\mathrm{pH}$ 8.0.

The contact of the serum with unwashed erythrocytes, both with and without the complement, did not lead to the agglutination and discoloration of the supernatant.

The addition of unithiol to the patient's serum led to the turbidity of the supernatant after the contact with unwashed erythrocytes. At $\mathrm{pH} 5.8$ the supernatant was more turbid and at $\mathrm{pH} 8.0$ - more transparent.

The contact of the complement with the erythrocytes and the serum treated with unithiol preserved the transparency of the supernatant, however at $\mathrm{pH}$ 5.8 the supernatant was turbid, whereas at $\mathrm{pH} 8.0-$ more transparent.

To determine the factors of the plasma, inducing the agglutination and complement-dependent hemolysis, we performed an incubation of the erythrocytes with standard $\operatorname{lgM} \alpha$ and $\beta$ and the complement as for the control.
The contact of IgM a with unwashed erythrocytes led to the red coloration of the supernatant and the agglutination. At pH 5.8 and 8.0 the hemolysis and the agglutination were also observed. The similar results were observed after the addition of the complement, but the erythrocytes under the microscope were larger in size and at pH 8.0 - somewhat smaller.

The reaction of $\operatorname{IgM} \beta$ with unwashed erythrocytes and the complement resulted in a transparent green supernatant and absence of the agglutination, at $\mathrm{pH}$ 5.8 - in a turbid green supernatant without the agglutination and at $\mathrm{pH} 8.0$ - in a transparent green supernatant without the agglutination.

The contact of unithiol-destroyed IgM $\alpha$ with unwashed erythrocytes and the complement led to a turbid supernatant and attenuation of the agglutination, at $\mathrm{pH} 5.8$ - to the turbid supernatant and a high degree agglutination and at $\mathrm{pH} 8.0$ - to the transparent supernatant and disappearance of the agglutination.

The contact of unithiol-destroyed IgM $\beta$ with unwashed erythrocytes and the complement led to the hemolysis and a turbid supernatant, at $\mathrm{pH} 5.8$ - to the severe agglutination and a turbid supernatant, without hemolysis, and at $\mathrm{pH} 8.0$ - to a pink supernatant and a large percentage of destroyed RBCs.

\section{Investigation of agglutination and hemolysis with washed erythrocytes}

When plasma was incubated with washed erythrocytes we did not observe the agglutination and hemolysis either at normal conditions or at $\mathrm{pH} 5.8$, but an addition of the complement led to the hemolysis with a pink colored supernatant without agglutination, whereas at $\mathrm{pH} 5.8$ the hemolysis was not observed. The incubation of the serum with washed erythrocytes did not lead to the agglutination and hemolysis, however, at $\mathrm{pH} 5.8$ the hemolysis was present. The addition of the complement to the serum and washed erythrocytes did not cause the agglutination and hemolysis, and at $\mathrm{pH} 5.8$ the supernatant was more transparent without agglutination. When plasma was incubated with washed nonheparinized erythrocytes we observed the agglutination without hemolysis.

While the incubation of the serum with washed nonheparinized erythrocytes at $\mathrm{pH} 5.8$ the hemolysis and the agglutination did not develop either, however an addition of the complement, as well as in the reaction with heparinized RBCs, resulted in the appearance of the hemolysis without agglutination and at $\mathrm{pH} 5.8$ the hemolysis was not observed either, however signs of weak agglutination were found. 


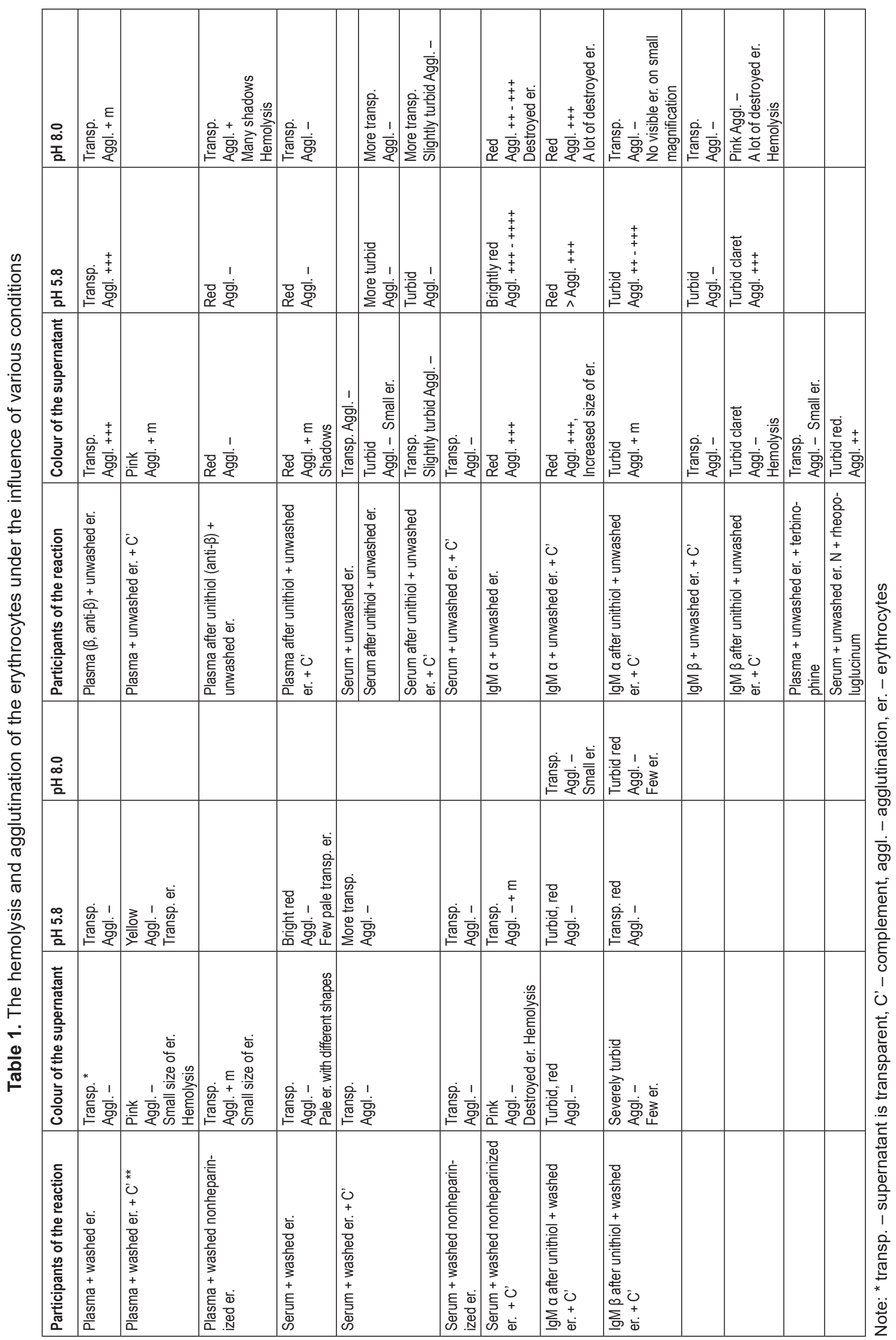


The destruction of $\operatorname{lgM} \alpha$ by unithiol in the reaction with the complement and washed erythrocytes led to a turbid red supernatant and hemolysis, but the agglutination observed with unwashed erythrocytes was absent both under usual conditions and at $\mathrm{pH}$ 5.8. At pH 8.0 the agglutination and hemolysis, as well as with unwashed erythrocytes, were absent, but the erythrocytes appeared to be smaller under the microscope.

After the usage of $\lg M \beta$ antibodies the hemolysis was not revealed, but after being destroyed, even with an addition of the complement the hemolysis appeared, apparently demonstrating the protective role of $\lg M \beta$ antibodies.

In contrast to the reactions with unwashed erythrocytes, the destruction of IgM $\beta$ by unithiol with the usage of washed erythrocytes and the complement led to the absence of the hemolysis under usual conditions and at $\mathrm{pH} 5.8$, as well as to the absence of the agglutination. Whereas at $\mathrm{pH} 8.0$ we observed the hemolysis without agglutination.

It should be noted that separately taken washed erythrocytes at $\mathrm{pH} 5.8$ were hemolysed.

The contact of rheopolyglucinum with serum and unwashed erythrocytes led to a turbid red colored supernatant and the agglutination. The use of terbinophine with plasma and unwashed red blood cells led to the absence of both the hemolysis and the agglutination.

Candida lusitaniae growth was detected in the plasma in 107 CFU.

\section{DISCUSSION}

The agglutination of unwashed erythrocytes under the influence of the patient's own plasma aroused our interest and prompted to perform a series of experiments.

The attenuation of the agglutination in the alkaline medium and the enhanced agglutination in the acid medium indicated an influence of $\mathrm{pH}$ on the activity of the antibodies in the plasma.

Since separately taken IgM $\alpha$ antibodies, regardless of the presence of the complement, led to the hemolysis and agglutination of the erythrocytes, and after being inactivated by unithiol no agglutination was observed, it could be assumed, that the antibodies present in the plasma belonged to a specificity. Since the agglutination was detected at $37^{\circ} \mathrm{C}$, but not at $20^{\circ} \mathrm{C}$, the patient had warm-reacting antibodies.

The presence of the immune hemolyzing antibodies in the plasma might be confirmed by the presence of the hemolysis in the experiment with the washed erythrocytes, plasma and the complement.

The absence of the hemolysis in the alkaline medium with the complement, as well as with the complement and plasma treated with unithiol (in the presence of $\lg$ ) can be explained by the loss of isoelectric properties of $\lg G$ and the attenuation of their activity [3].

In the experiments carried out the destruction of the erythrocytes was also observed without any participation of the complement.

The turbidity of the supernatant in the reaction of the erythrocytes with the serum treated with unithiol indicates the worsening of the bactericidal properties of the serum after destruction of the protective IgM.

After the destruction of $\operatorname{lgM} \beta$ and the usage of the complement the initially absent hemolysis appeared, indicating the protective role of $\operatorname{IgM} \beta$ antibodies in nonimmune hemolysis.

The presence of a stronger agglutination in the acid medium, regardless of the participants of the reaction, indicated an increased potential of the acid medium on the agglutination. Considering the fungal ethiology we used terbinophine, that prevented both the agglutination and hemolysis under the influence of the plasma and the complement. Our data are in accordance with those of Sudd et al. on the ability of Candida to initiate the agglutination [7]. It might be possible that adsorption of the antigens of fungi (adhesins, D-lactose) on the surface of the erythrocytes led to the agglutination by $\beta$ antibodies present in the serum (by the type of indirect hemagglutination reaction), since with washed erythrocytes the agglutination was not observed, even at $\mathrm{pH} 5.8$, however the hemolysis (apparently due to the immune mechanisms) was present.

The autoagglutination of the fungal or bacterial origin has an interesting pathogenesis $[8,9]$ - bacterial or fungal glycosylases cleave monosaccharide and acetyl groups of glycoproteins and glycolipids on the membrane with release of cryptagglutinogens $[10,11]$. Thus, modified erythrocytes are easily agglutinated by $\lg \mathrm{M}$. The cryptagglutinogens may be detected by lectins.

Thus, we assume the presence of warm-reacting autoantibodies in the examined patient with periprosthetic infection after arthroplasty. The patient had manifestations of complement-dependent hemolysis mediated by IgG and complement-independent hemolysis caused by the fungal agent, since the usage of terbinophine abolished the hemolysis, and bacteriological investigation of the plasma showed growth of Candida lusitaniae. The manifestations of 
the complement-dependent hemolysis observed in this patient can serve as an example of autoimmune reaction with the complement participation in a complicated course of the inflammatory process.

\section{CONCLUSIONS}

The presented data show the complexity and cooperation of the processes of anti-infectious protection and immunoregulatory reactions involving the complement. The presence of the complement-dependent hemolysis can influence the development of the anti-infective response and lead to the complicated course of the postoperative period.

Conflicts of interest: There are no conflicts of interest to declare.

Disclosure Summary: The authors have nothing to disclose.

\section{REFERENCES}

1. Quist E. Autoimmune Hemolytic Anemia and Red Blood Cell Autoantibodies. Quist E., Koepsell S. Arch Pathol Lab Med. 2015,11(139)1455-8. doi: 10.5858 / arpa.2014-0337-RS.

2. Blackall D.P. Warm-reactive autoantibodies in pediatric patients: clinical and serologic correlations. J Pediatr Hematol Oncol. 2007, 11(29) 792-796.
3. Wheeler C.A, Calhoun L., Blackall D.P. Warm reactive autoantibodies: clinical and serologic correlations. Am J Clin Pathol. 2004,5(1) 680-685.

4. Zantek N.D., Koepsell S.A., Tharp D.R. Cohn CS. The direct antiglobulin test: a critical step in the evaluation of hemolysis. Am J Hematol. 2012,87(7) 707-709.

5. Marsh W.L. Scoring of hemagglutination reactions. Transfusion. 1972(12) 352-3.

6. Delevsky Yu. P., Dielievska V. Yu. Antigen-antibody electrostatic interactions in the ab0 blood system. Весці нацыянальнай акадэміі навук беларусі. Серыя медыцынскіх навук. 2016(1) Р. 44-51.

7. Judd W.J. Microbial-associated forms of polyagglutination ( $T$, Tk and Acquired B) Beck M.L., Judd W.J., eds. Polyagglutination: A Technical Workshop. 1st ed. Washington DC: American Association of Blood Banks. 1980, 23-53.

8. Judd W.J. Review: polyagglutination. Immunohematology. 1992;8(3):58-69.

9. Joshi S.R., Naik R.A., Gupte S.C. Unusual spontaneous cold auto-hemagglutination phenomenon in blood units stored under blood bank condition: A retrospective analysis. Asian J Transfus Sci. 2015(9) 141-4.

10. Beck M.L. Blood group antigens acquired de novo. Garratty $\mathrm{G}$, ed. Blood group antigens and disease. Arlington, VA: American Association of Blood Banks. 1983, 45-66.

11. Bird G.W. Clinical aspects of the red blood cell polyagglutinability of microbial origin. Blood Groups and Other Red Cell Surface Markers in Health, 1982.

Received: April, 2019 - Accepted: May, 2019 